\title{
Estado de la investigación sobre procesos de desmovilización en excombatien- tes de grupos al margen de la ley en Colombia (2006-2016) ${ }^{1}$
}

\section{State of the research on demobilization processes in ex-combatants of groups outside the law in Colombia (2006-2016)}

\author{
José Alexander Herrera Contreras ${ }^{2}$ \\ jose.herrera@unad.edu.co \\ Carolina García Galindo ${ }^{3}$ \\ carogarciagalindo@yahoo.com
}

\section{Resumen}

El artículo muestra el estado de la investigación sobre procesos de desmovilización de excombatientes de grupos al margen de la ley durante el periodo (2006 - 2016). Se hizo una revisión documental de artículos científicos aparecidos en revistas indexadas y libros publicados por editoriales académicas. Las categorías de análisis construidas son: Problemas de investigación, perspectivas teóricas y perspectivas metodológicas. En relación con los problemas de investigación sobresalen: Reincidencia, Condiciones de vida de los desmovilizados, Consecuencias de la desmovilización, Motivos de la desmovilización y Efectos políticos de la desmovilización. Las perspectivas teóricas son analizadas desde: Psicosociales, Sociológicas y Políticas. Los abordajes metodológicos son mayoritariamente cualitativos, siguiendo documentales, cuantitativos y finalmente mixtos. Las conclusiones indican gran avance en investigaciones relacionadas con procesos de desmovilización colectivo, y escasa revisión en procesos de desmovilización individual.

Palabras clave: Procesos de desmovilización; Excombatientes; Grupos guerrilleros: (FARC) - (ELN); Paramilitares; (AUC); Conflicto armado en Colombia.

\section{Abstract}

The article shows the state of the research on processes of demobilization of ex-combatants of groups outside the law during the period (2006 - 2016). A documentary review of scientific articles appeared in indexed journals and books published by academic publishing houses. The categories of analysis constructed are: Research problems, theoretical perspectives and methodological perspectives. In relation to the research problems, they stand out: Recidivism, Living conditions of the demobilized, Consequences of the demobilization, Reasons for the demobilization and Political effects of the demobilization. The theoretical perspectives are analyzed from: Psychosocial, Sociological and Political views. The methodological approaches are mostly qualitative, following documentary, quantitative and finally mixed. The conclusions indicate great progress in research related to collective demobilization processes, and little review in individual demobilization processes.

Keywords: Demobilization processes; Veterans; Guerrilla groups: (FARC) - (ELN); Paramilitaries; (AUC); Armed conflict in Colombia.

\footnotetext{
${ }^{1}$ Artículo de revisión. El trabajo se inscribe en el proceso de investigación adelantado en el marco del desarrollo del Programa de Doctorado en Ciencias Sociales, a través de la Universidad Autónoma del Estado de México cuya investigación ha sido denominada: Análisis de la decisión individual en procesos de desmovilización con estudiantes excombatientes de grupos al margen de la ley de una universidad pública en Colombia.

${ }^{2} \mathrm{Mg}$. en Investigación Social Interdisciplinaria. Universidad Nacional Abierta y a Distancia - UNAD. ORCID https://orcid.org/0000-0001-7505-9451

${ }^{3} \mathrm{Mg}$. of Arts in Education - Higher Education. Docente en la Universidad Nacional Abierta y a Distancia - UNAD Florida - Estados Unidos. ORCID https://orcid.org/0000-0002$8154-4692$

${ }^{*}$ Cómo citar este artículo: Herrera, J. \& García, C. (2018). Estado de la investigación sobre procesos de desmovilización en excombatientes de grupos al margen de la ley en Colombia. Hojas y Hablas, (15), 11-33. DOI: 10.29151/hojasyhablasn.15a1
} 
Estado de la investigación sobre procesos de desmovilización en excombatientes de grupos al margen de la ley en Colombia (2006-2016)

\section{Introducción}

En Colombia hay un conflicto armado que involucra a la Fuerza Pública, guerrilla y paramilitares, y grupos al margen de la ley asociados al narcotráfico. Entre las décadas de los sesenta, setenta y ochenta se conformaron la mayoría de grupos guerrilleros: Fuerzas Armadas Revolucionarias de Colombia (FARC), Ejército de Liberación Nacional (ELN), Movimiento Armado Quintín Lame, Ejército Popular de Liberación (EPL), Movimiento 19 de abril (M-19), Partido Revolucionario de los Trabajadores (PRT), Comandos Ernesto Rojas, Corriente de Renovación Socialista, Milicias Populares de Medellín, y el Frente Francisco Garnica. Posteriormente, en la década de los años ochenta se presentó el surgimiento de los grupos paramilitares, relacionados y apoyados estos últimos por grupos de terratenientes, militares, elites políticas y narcotráfico.

Desde la lógica de dar solución política al conflicto desde el año de 1958 los mandatarios han impulsado acuerdos de paz con los diferentes grupos armados insurgentes. En tal contexto, en relación con los grupos guerrilleros es posible identificar tres grandes momentos: el primero se realizó entre las guerrillas campesinas del Llano y el gobierno del General Gustavo Rojas Pinilla. El acuerdo permitió el desmonte de las ya guerrillas liberales entre 1955 y 1958. El segundo gran acuerdo de paz se desarrolló durante el gobierno del Presidente Belisario Betancourt (1982 - 1986) proceso que fue adelantado entre las FARC, el EPL y el M-19 y el Gobierno; este acuerdo permitió la creación de la Unión Patriótica (UP). Sin embargo, dos de sus candidatos presidenciales fueron asesinados y la mayoría de sus simpatizantes corrieron con la misma suerte hasta el punto de configurar un genocidio político.

El tercer gran acuerdo se llevó a cabo en el gobierno de Cesar Gaviria (1990 - 1994) en el marco de una Asamblea Nacional Constituyente y posterior reforma política, en el que se desmovilizaron el Movimiento Armado Quintín Lame, Ejército Popular de Liberación (EPL), Partido Revolucionario de los Trabajadores (PRT), Comandos Ernesto Rojas, Corriente de Renovación Socialista, Milicias de Medellín, Frente Francisco Garnica y el M-19 que fue el primero en firmar y luego, cuando ya había sido convocada la Asamblea Constituyente, lo hicieron el EPL, El PRT, EL Quintín Lame y varios milicianos de Medellín.

De lo anterior, a excepción del (M-19), cuyo acuerdo de paz brindó las posibilidades para la conformación de un partido político denominado Alianza Democrática $(\mathrm{AD})$, varios excombatientes de los grupos guerrilleros desmovilizados serían asesinados por grupos paramilitares, fuerzas militares y grupos de seguridad privada, una vez se reinsertaron a la sociedad civil. Por otro lado, algunos disidentes del (M-19) conformaron un grupo conocido como: Jaime Bateman Cayón que posteriormente algunos de sus miembros se unirían a las filas de las (FARC-EP) en el Cauca.

Con relación a los grupos paramilitares, el acuerdo de paz se celebró durante el periodo presidencial de Álvaro Uribe Vélez $(2002$ - 2010) por medio de la Ley de Justicia y Paz, de la cual se desmovilizaron aproximadamente 30.000 combatientes. El proceso de desmovilización prosperó en medio del rechazo por parte de las víctimas, toda vez que la mencionada Ley no atendía de forma adecuada el proceso de Justicia Transicional en contra de varios excombatientes acusados de crímenes de lesa humanidad. De ahí que algunos resultados del Acuerdo de Paz han sido el retorno a las armas por medio de la constitución de Bandas Criminales (BACRIM) por parte de los ex - paramilitares, destinadas al negocio del microtráfico y 
monopolio de territorios urbanos y rurales. Es importante señalar que los grupos paramilitares no eran opositores del gobierno, lo que se hizo fue un acuerdo de sometimiento a la justicia, que derivó en la extradición de varios líderes paramilitares y la entrega de parte de sus bienes, pero no enjuiciamientos por masacres de población.

Este breve recorrido por los procesos de negociación con los grupos insurgentes vislumbra cierto enraizamiento del conflicto colombiano. (Ver anexo 1) La Constitución de 1991 se particularizó en medio de un escenario político que exigía resolver una grave crisis institucional, se particularizó también en una estrategia para "normalizar" el país y brindar las condiciones sociales que darían paso a la apertura económica, y finalmente se particularizó en el esfuerzo por canalizar procesos de desmovilización con las guerrillas. El Estado en su esfuerzo por atender las especificidades guerrilleras, olvido que la reforma política representaba un camino para transformar las condiciones estructurales que inauguraron y sostenían el conflicto social-armado. En medio de intereses propios y ajenos, el agotamiento del mantenimiento de la confrontación armada, un momento histórico que vislumbraba oportunidades políticas, la necesidad de legitimación institucional, y la apertura a un nuevo contexto económico; la reforma política no significó la institución de un nuevo contrato social, sino que su contribución mayor fue ablandar los reclamos sociales, pacificar una parte del país, y menguar el movimiento insurgente. No obstante, la validez de la Constitución Política de 1991, configuró un consenso determinante y legítimo.

En las raíces del conflicto en Colombia se tejen aspectos culturales, simbólicos, imaginarios, identitarios, y la construcción de una representación de la violencia en la memoria colectiva del pueblo colombiano, cuyo escenario lo hace más complejo de resolver a través de un tratado de paz. Es posible precisar que con la excepción de los disidentes del (M-19) los acuerdos de paz han sido tramitados con base en las condiciones políticas planteadas por el gobierno en turno, no obstante, el acuerdo de paz más ceñido a los parámetros gubernamentales fue el del M19, los otros giraron en torno a la ANC en medio de un gobierno saliente y uno entrante, ambos sin claridad lo cual ha determinado en cierta medida un fracaso en la dejación de las armas toda vez que algunos excombatientes han retornado a las armas, otros han sido asesinados o su acción bélica se ha transformado en otros modos de violencia. El retorno a las armas por parte de varios excombatientes no significa el fracaso de los acuerdos, muchos de ellos, sino todos, aspiraban a crear condiciones para el logro de paz con justicia social y no solo de paz armada. Otra cosa en consecuencia es, el fracaso de obtener paz con justicia social.

En relación con lo anterior, es necesario contextualizar que los acuerdos de paz con los grupos ilegales han sido realizados de manera paralela al conflicto armado. En Colombia, los diálogos de paz se presentan en medio del sostenimiento del conflicto lo que ha ocasionado que tanto grupos guerrilleros y paramilitares tengan reservas al momento de la desmovilización, en especial por la vulnerabilidad a la que quedan expuestos los combatientes y en particular por las expresiones de violencia en contra de los excombatientes a cargo del grupo contrario, o inclusive enmarcadas en una política criminal de orden estatal.

La contribución que espera generar el texto se propone en dos sentidos: hacer análisis de los análisis hechos a la problemática planteada y avanzar en el análisis de los procesos de desmovilización, a nivel teórico y metodológico. 
Estado de la investigación sobre procesos de desmovilización en excombatientes de grupos al margen de la ley en Colombia (2006-2016)

Desde estas consideraciones, el objetivo del presente artículo tiene como propósito ofrecer una revisión actualizada sobre el estado de avance de la investigación en procesos de desmovilización en excombatientes de grupos al margen de la Ley en Colombia (2006-2016); no obstante, han sido revisados textos de años anteriores que por su profundidad y análisis teórico merecieron ser parte de la revisión. Para tal fin, la información ha sido clasificada en tres categorías: Problemas de investigación, Perspectivas teóricas y Perspectivas metodológicas.

Con relación a la elección de las categorías han sido construidas en el esfuerzo de resolver la pregunta: Cuáles problemas han sido planteados en investigaciones sobre procesos de desmovilización en excombatientes de grupos al margen de la Ley en Colombia (2006-2016), a la luz de qué perspectivas teóricas han sido analizados y cómo han sido realizados los procesos de análisis. En consecuencia, las categorías recogen los tres aspectos más relevantes orientados por el proceso de comprensión y estudio del autor.

\section{Metodología}

La información ha sido recogida a través de la revisión en bases de datos como: Redalyc, Clacso, Proquest, Scopus, Ebsco host, Scielo reuniendo 13 libros y 74 artículos científicos para una suma de 87 investigaciones relacionadas con el objeto de estudio. La revisión se hace tomando en cuenta las investigaciones más recientes en el tema y considerando que desde el año 2006 se da prelación al programa de desmovilización individual. Las bases de datos son de consulta abierta. Todos los artículos han sido analizados desde tres categorías: Problemas de investigación, Perspectivas teóricas y Perspectivas metodológicas.
Con relación a la elección de las categorías han sido construidas en el esfuerzo de resolver la pregunta: Cuáles problemas han sido planteados en investigaciones sobre procesos de desmovilización en excombatientes de grupos al margen de la Ley en Colombia (2006-2016), a la luz de qué perspectivas teóricas han sido analizados y cómo han sido realizados los procesos de análisis. En consecuencia, las categorías recogen los tres aspectos más relevantes orientados por el proceso de comprensión y estudio del autor.

\section{Problemas de investigación}

Los problemas que han abordado los investigadores se concentran en cinco dimensiones: reincidencia, condiciones de vida de los desmovilizados, consecuencias de la desmovilización, motivos de la desmovilización y efectos políticos de la desmovilización. En relación con los estudios que hablan sobre la reincidencia se encuentra el trabajo realizado por Llorente (2014), que parte de la pregunta por qué algunos excombatientes retornan a la ilegalidad mientras otros se reintegran exitosamente a la vida civil. Allí el autor señala que comprender la reincidencia permitirá identificar los factores de riesgo asociados al fenómeno. El estudio corroboró que el programa de reintegración es eficaz para los desmovilizados individuales los cuales son mayoritariamente guerrilleros y han estado en el programa por convicción o decisión; en cambio, con relación a los desmovilizados en condición de colectivos, especialmente los paramilitares, estos presentan mayor tasa de reincidencia, retornando a la ilegalidad.

La experiencia durante la guerra cambia a los sujetos y determina su intención de reincidir. A nivel individual surgen dos factores para reincidir: La exposición al conflicto y el rango en la organización armada. El primer factor implica el 
repertorio y la cantidad de violencia experimentada, es decir, a mayor nivel de violencia más alto el riesgo de reincidencia. El segundo factor tiene relación con el rango que adquirió durante su participación en la guerra, o sea, a mayor grado de poder mayor riesgo de reincidencia, a mayor experiencia de guerra mayor grado de reincidir.

Los resultados sugieren que las motivaciones por las que los sujetos deciden ingresar a la guerra no son buen predictor de reincidencia o reintegración. Los combatientes que ingresaron al grupo armado por un descontento general (agravio) tienen la misma probabilidad de reincidir que aquellos que se vincularon por motivos personales (venganza). De acuerdo con los datos del total de desmovilizados colectivos , 23\% se desmovilizó por orden directa (Llorente, 2014). A partir de esto, el autor identificó que desmovilizarse en contra de la voluntad está relacionado directamente con la reincidencia; y a su vez, la desmovilización involuntaria está relacionada con la proclividad a reincidir. Entre los factores psicológicos se encontró que a mayor nivel de remordimiento por haberse desmovilizado (desertor) mayor vulnerabilidad a la reincidencia.

En la misma lógica para explicar el fenómeno de la reincidencia, Nussio (2009) analiza la desmovilización de los grupos paramilitares -2006- cuyo hallazgo es que los excombatientes persistieron en mantener las estructuras de control y continúan prestando servicio de seguridad privada. El autor identifica que la reincidencia en este caso se puede explicar a través de seis factores (razones económicas, falta de seguridad física, falta de participación política, falta de aceptación social, presencia de perturbadores de paz, y ausencia del Estado).
La participación del Estado frente a la reincidencia de excombatientes ha sido indagada a partir del proceso de desmovilización con los grupos de las Milicias Populares de Medellín (MPM). El proceso de desmovilización con estos grupos se realizó en el año 1994 en que el gobierno como estrategia de reintegración para los excombatientes y fortalecimiento en la lucha antisubversiva implementó las Coosercom que se conocerían como Convivir y cuyo objetivo era garantizar la seguridad en los barrios y comunas. Estas Convivir, más adelante se transformaron en grupos paramilitares, como el Bloque Cacique Nutibara.

Entre los procesos de desmovilización de grupos guerrilleros y paramilitares, la reincidencia se ha manifestado con mayor fuerza en los segundos. Restrepo y Franco (2007) identificaron que el proceso de desmovilización con los grupos paramilitares se enmarcó en una dinámica de reorganización ofensiva. La persistencia del paramilitarismo se explica por la función que le ha sido atribuida en el desarrollo de la guerra contra la insurgencia, esto supone una estrategia de desdoblamiento de la acción armada con el propósito de conservar la fuerza.

Otro de los problemas investigados ha sido indagar por las condiciones de vida de los desmovilizados. En este sentido aparece el factor seguridad para los desmovilizados, toda vez que se han registrado homicidios o actos de violencia contra ellos. Frente al proceso de desmovilización de los bloques Cacique Nutibara y Héroes de Granada en Medellín, Alonso \& Valencia (2008) encontraron que durante 2007 fueron asesinados 120 excombatientes. Tal situación permitiría pensar que el rearme de los desmovilizados se debe en parte a la misma situación de inseguridad por la que atraviesan, de hecho, en ocasiones han sido los mismos desmovilizados (compañeros combatientes) 
Estado de la investigación sobre procesos de desmovilización en excombatientes de grupos al margen de la ley en Colombia (2006-2016)

los que han ejecutado los crímenes.

La percepción de calidad de vida aparece como otro factor de análisis; por tanto, en el estudio realizado por Velasco \& Londoño en 2011, se identificó que los desmovilizados que habían hecho parte de grupos guerrilleros manifestaron tener mejor calidad de vida en comparación con los desmovilizados de grupos paramilitares. Llama la atención que el tipo de desmovilización (individual o colectiva) se relaciona con la calidad de vida en los desmovilizados. En consecuencia, la desmovilización cuando se presenta de manera colectiva genera mayor percepción de calidad de vida subjetiva, contrario sucede cuando la desmovilización se presenta en forma individual.

Aspectos como educación, salud y trabajo garantizados de forma favorable permitirían suponer un adecuado proceso de reintegración; sin embargo, Chavarría (2012) adelantó una investigación con los sujetos desmovilizados que hicieron parte del programa de Paz y Reconciliación adelantado por la Alcaldía de Medellín durante el año 2005, entre sus hallazgos se precisa que la efectividad del programa ha tenido éxito en aquellos excombatientes que junto con la entrega de las armas también encontraron en la desmovilización una alternativa de vida, a diferencia de los excombatientes que desertaron del programa.

Otro factor de indagación frente al tema de las condiciones de vida de los desmovilizados es el estudio de las redes personales, toda vez que éstas representan el apoyo social real y/o percibido y que deviene como un vínculo de amarre psicológico que facilita los procesos de reintegración. Además, la construcción y mantenimiento de dinámicas de socialización en los nuevos escenarios comunitarios demuestra ser un aspecto positivo en las condiciones de vida de los desmovilizados (Amar, Abellos, Madariaga \& Ávila, 2011; Ávila \&
Cogollo 2011; Farfán \& Álzate, 2010; Madariaga \& Ávila, 2010; Meneses \& Devia, 2010; Tamayo, Restrepo \& Gutiérrez 2011).

Como tercer problema de investigación se encuentran las consecuencias de la desmovilización; en relación con esto se hace posible clasificarlas en individuales y colectivas. A nivel individual ha surgido el interrogante por las consecuencias psicológicas de la desmovilización. En ese sentido, algunas investigaciones mencionan que se presenta un quiebre subjetivo, una discontinuidad en el proyecto de vida, una reconfiguración de la propia individualidad (Aranguren, 2011; Aguirre, 2014; Barrera, 2014; Blom \& Pereda, 2007; Carmona, 2014; Correa, 2007; García \& Mongua, 2010; Londoño \& Blair, 2007; López, 2011; Moreno, Carmona \& Tobón, 2010; Ocampo, Baracaldo, Arboleda \& Escobar, 2014).

Otras manifestaciones que presentan hombres y mujeres al pasar de la vida armada a la vida civil como consecuencia de la desmovilización individual son los procesos de reconfiguración de la identidad, la redefinición del amigo y del enemigo, la recuperación de la familia, el oficio, la autoridad y el proyecto vital. Hablamos entonces de un proceso que enfrenta a mujeres y hombres excombatientes a la necesidad de recomponer su identidad y silenciar su pasado; en una dialéctica subjetiva que adicionalmente no puede ser exclusiva individual, sino que necesita también un escenario social, del Otro.

El sujeto excombatiente plantea un retorno a lo que había renunciado, supone también una fractura con un colectivo que comporta un ideal y, finalmente, conlleva a asumir una responsabilidad que ya no se puede diluir en el amparo del grupo guerrillero o paramilitar. El nivel de análisis del sujeto excombatiente va más allá del acto que supone la entrega de las armas, el esfuerzo señala una nueva 
dimensión ética hacia la comprensión del fenómeno de la desmovilización; se establece de esa manera un escenario convocado por el sujeto excombatiente envuelto entre una obediencia ciega y la responsabilidad que le implica como sujeto. De lo anterior se entiende que el tránsito a la vida civil debe abrigar la carga subjetiva que jalona el combatiente, a pesar que la decisión sea individual o colectiva, el pasaje subjetivo despliega una ruptura y un mundo de significación que debe ser puesto en palabras en los amarres del significante (Bello \& Ruiz, 2002; Castro, 2001; Díaz, 1997; Espriella, 2009; Londoño \& Nieto 2006; Leliévre, Moreno \& Pérez, 2004; Patiño \& Patiño, 2012; Salcedo \& Salazar, 2010; Theidon, 2009; Villarraga, 2013).

A nivel colectivo, las consecuencias de la desmovilización van desde la conformación de nuevos grupos de violencia conocidos como bandas criminales (BACRIM), hasta la construcción de un favorable escenario de posconflicto. Las conclusiones alrededor del proceso de desmovilización con los grupos paramilitares (Aranguren, 2012; Escobar, 2013; Méndez \& Botero, 2008; Noreña, 2007; Pérez, 2008; Querubín, 2010; Reyes, 2013) indican que el proceso de negociación estuvo caracterizado por inconsistencias políticas. La desmovilización realizada por los grupos paramilitares entre el periodo (2006 - 2010) se limitó a un desarme de ciertas agrupaciones ubicadas particularmente en zonas como: Magdalena Medio, Córdoba y Llanos Orientales, y a la reorganización de nuevos grupos criminales. Es importante señalar que excombatientes de grupos guerrilleros han regresado a las armas por medio de su vinculación a agrupaciones paramilitares. No obstante, las (BACRIM) han sido conformadas mayoritariamente por excombatientes de grupos paramilitares.

A partir de este eje de análisis, Cárdenas (2006) señala que los procesos de desmovilizacio- nes han finalizado en medio de contradicciones. Un primer elemento que se debe considerar es que no se ha presentado una entrega completa de armamento, lo que ha determinado que el cese de hostilidades no haya sido respetado, esto afianza las dudas sobre la transparencia del proceso y las posibilidades de rearme. Al respecto, la misión de verificación de la Organización de Estados Americanos (MAPP/OEA) ha señalado que varios bloques paramilitares dejaron instaladas estructuras paralelas con el propósito continuar manejando el negocio del narcotráfico, extorsiones y otros delitos. De hecho, entre junio y diciembre de 2005, las autoridades detectaron 13 nuevos grupos paramilitares actuando en zonas en donde se habían producido desmovilizaciones. (Hübschmann, 2016)

Por tanto, el postconflicto, entendido como una consecuencia positiva de los procesos de desmovilización, deberá avanzar en la construcción de alternativas hacia la construcción de paz perdurable como medidas para no recaer en el conflicto de orden bélico, y entender de manera amplia la participación de cada uno de sus actores, para el caso en particular, cada uno de los excombatientes. El postconflicto marca una ruta hacia una expectativa de paz, no obstante, el escenario de postconflicto ha sido elevado hacia un proyecto de nación, cuyo horizonte determinará por fin la paz en Colombia. En ese sentido, la etapa del postconflicto señalará las formas y opciones de reintegración política para excombatientes, tanto de grupos guerrilleros o paramilitares, en el marco de la reconciliación nacional, garantía de no repetición y participación ciudadana. (Giraldo, 2010; Rampf \& Chavarro, 2005; Roldan, 2013; Ugarriza, 2013).

El cuarto problema de investigación está relacionado con los motivos para la desmovilización. Las investigaciones giran en torno a ubicar 
Estado de la investigación sobre procesos de desmovilización en excombatientes de grupos al margen de la ley en Colombia (2006-2016)

al sujeto excombatiente en escenarios colectivos más no individuales. Los motivos de los excombatientes paramilitares pueden ser ubicados en tres variables: orden directa, ausencia del tributo económico y acceso a beneficios del Estado (Céspedes, 2015; Gutiérrez, 2012; Gunhild \& Luisa, 2007; Herrera \& González, 2013; Nussio, 2013; Sánchez \& Suarez, 2013).

Los motivos para la desmovilización en excombatientes guerrilleros pueden ser subjetivos. Entre los motivos encontrados frecuentemente en hombres se encuentran: reencuentro familiar, problemas con compañeros o comandantes y diferencia hacia la organización. En las excombatientes mujeres se encuentran: derecho a la maternidad, violencia física y sexual en algunos casos y discrepancia con la causa guerrillera. (Cárdenas, 2005; Carmona, 2012; Keairns, 2004; Suarez, Patiño \& Aguirre, 2011; Valencia \& Daza, 2010)

Los motivos para la desmovilización guardan estrecha relación con los motivos para la vinculación. La participación en una organización armada ilegal se inscribe bajo condiciones sociales que determinan la vinculación. De modo que, el sujeto combatiente encuentra en los grupos armados elementos psicosociales que hacen tránsito para la vida armada, aspectos como: el poder ejercido a través del uso de las armas, la construcción de la masculinidad tanto en hombres como en mujeres, y la configuración de la nueva identidad bajo la lógica de un proyecto armado son analizados en forma recurrente.

A diferencia de los procesos de desmovilización colectivo que por lo general se matriculan en acuerdos de paz, la desmovilización individual desgarra por completo los lazos grupales que se construyen al interior de la organización armada en la medida que, además de convertirse en el reemplazo inmediato de la familia, el colectivo se constituye en el referente central de quienes hacen parte de la organización armada ilegal. En relación con las formas de desmovilización individual, éstas se presentan de maneras diferentes: en anonimato, pero con ayuda de la comunidad o negociación con la familia, por captura, por decepción por la causa, agotamiento físico y emocional, muertes de familiares o amigos, embarazos y desprendimiento de lazos afectivos (Nussio, 2011).

Así entonces, se encuentra que con respecto a la desvinculación individual en organizaciones guerrilleras la literatura sitúa al excombatiente (desertor) como un sujeto cuya desmovilización se produce motivado en parte por situaciones de adversidad social, temor a la muerte, problemas internos con la organización armada, fractura en la apuesta ideológica o sugestión por parte de familia o pareja; estos factores son identificados entre los motivos que conducen a la desmovilización individual; sin embargo, el análisis del sujeto cuya decisión pasa por lo singular y subjetivo, es enunciado por (Castro, 2001), quien advierte que hay algo de lo particular del sujeto que se coloca en juego al momento de ingreso y salida del grupo armado y que tiene que ver con la construcción de sus significantes, significados y por supuesto de la subjetividad, se habla entonces de una elección subjetiva para el ingreso y salida del grupo armado ilegal.

Desde estas consideraciones surgen puntos de encuentro como: en la vinculación y posterior desmovilización individual se configuran elementos sociológicos que operan como determinantes al momento de la desmovilización (pobreza, violencia, seguridad, proyecto de vida). Las intersecciones señalan que la vinculación y desvinculación articula elementos psicosociales que se colocan en juego antes, durante y después del paso 
por la guerra. En relación con lo singular del sujeto excombatiente, la construcción de la decisión por la desmovilización implica transitar hacia una mirada dialéctica en donde la decisión encara un entrar y salir entre lo individual y colectivo, es una decisión dialéctica, es una construcción dialéctica.

Los efectos políticos de la desmovilización como el quinto problema de investigación se enmarcan en dos efectos principalmente. La conformación de partidos políticos, fundaciones u ONG y la coacción o influencia que puedan ejercer los recientes desmovilizados en sus antiguas zonas de control. Al respecto habrá que decir también que, en el tema de reparación a las víctimas y a la sociedad, la dimensión o alcance de un acuerdo de paz no logrará llegar a ese punto de exigencia, pero será a través de una salida política para los insurgentes como puede resolverse el conflicto armado.

Al respecto, Rincón (2010) entiende que el fenómeno de violencia en Colombia plantea un marco de análisis que no solo se pregunta por los actores, las circunstancias y las consecuencias de la guerra, sino que se desarrolla en un marco de grandes complejidades históricas, geográficas, culturales y sociales. La historia del conflicto colombiano se ha definido en una compleja amalgama caracterizada por una herencia de décadas de violencia incesante, un complicado sistema de creencias que varían de un lugar a otro de la geografía nacional y una cadena histórica de procesos de paz inconclusos y generadores de impunidad.

Es importante comprender que los acuerdos de paz vienen a operar como mecanismos de relación a través de los cuales los actores de un conflicto ajustan relaciones de poder previamente existentes. En ese orden de ideas, el poder de coacción que adelantan los desmovilizados (con mayor énfasis en grupos paramilitares) al momento de las contiendas políticas debe ser entendido como un efecto político de la desmovilización (Bácaras, 2015; Caraballo, 2013; Grajales, 2011; Jiménez \& Ramírez, 2016; Losada, 2006; Montalvo, 2015; Vizcaíno \& Molina, 2016).

En relación con la conformación de partidos políticos, asociaciones de excombatientes o inclusive como se mencionó arriba ONG, se vislumbra como uno de los mejores efectos políticos que pueda tener un acuerdo de paz. Entender el surgimiento de guerrillas, paramilitares, su vigencia y degradación hasta la necesidad de poner fin a esta situación mediante una búsqueda de paz que incluya formas de participación política para quienes se desmovilicen, son los resultados que presentan investigaciones en ese tema (Castillo \& Boris, 2009; Echeverría, 2007; Gómez, 2002; Gutiérrez, Guzmán, Barrera, Forero, Prada, Valderrama, 2010; Nasio, 2007; Leal, 2013).

Es importante resaltar que frente a los efectos políticos de la desmovilización se debe entender que la participación política a través de un partido o movimiento permitirá en los excombatientes dar trámite a sus malestares propios y colectivos. Además, en Colombia de no contar con las condiciones favorables hacia la inclusión política de los desmovilizados con el apoyo de la comunidad internacional, difícilmente prosperará alguna iniciativa de paz que no augure el fracaso de algún intento por buscar una salida negociada al conflicto.

\section{Perspectivas teóricas}

Las perspectivas teóricas entraña ofrecer una respuesta desde cuáles enfoques o teorías han sido comprendidos los problemas de investigación, estas "gafas" teóricas han sido agrupadas en tres grandes perspectivas: psicosociales, sociológicas y políticas. Es importante aclarar que en rela- 
Estado de la investigación sobre procesos de desmovilización en excombatientes de grupos al margen de la ley en Colombia (2006-2016)

ción con la perspectiva psicosocial ha sido subdividida en las subjetivas y las psicológicas.

En relación con la perspectiva psicosocial a la luz de la subjetividad sobresalen investigaciones que entienden el fenómeno de la desmovilización desde la implicación subjetiva que comporta, es decir, son propuestas que están relacionadas con el concepto de subjetivación social. En ese sentido, Theidon (2009) aborda la teoría de identidad social alrededor de la construcción de la masculinidad en escenarios de guerra. Los vínculos entre armas, masculinidad y violencia están fijados en el escenario de la guerra colombiana. Las motivaciones para ser parte de los grupos armados guarda relación con las formas violentas de construir la masculinidad. La desmovilización implica, por tanto, desmontar la masculinidad del combatiente y reconstruir lo que significa ser hombre.

El interaccionismo simbólico es otro concepto utilizado por investigaciones que indagan en el análisis del excombatiente desde una dimensión del self (Carmona, 2012; Moreno, 2010). La apuesta teórica desde este escenario conceptual es orientada desde una perspectiva dialéctica, y a partir de allí se posibilita construir un sujeto responsable, esto supone desde los estudios realizados por Carmona y Moreno sobre niñas y niños excombatientes, que las niñas y niños excombatientes plantean sus vidas en el momento en que construyen el plan de acción de vincularse a los grupos armados y en cada decisión que toman en su avatar guerrillero o paramilitar.

Las investigaciones de Aranguren, $2011 \mathrm{y}$ Carmona, 2006 utilizaron las teorías sobre identidad, subjetividad social (González, 1999) subjetivación social (Castro, 2001), que explican cómo a través de la participación y desmovilización de mujeres y hombres la exposición del cuerpo es en- trenado para el combate y ocurre un adoctrinamiento de la sexualidad que se pone en juego en un contexto ilegal. Por tanto, a mayor asimilación de lo masculino (entendiendo que el escenario armado es mediado por factores psicosociales como el manejo de armas y militancia que vienen a ser considerados prácticas masculinas), más difícil será el proceso de regreso a la civilidad, presentándose una cierta lesión emocional consecuencia de la experiencia.

María Clemencia Castro desde el enfoque psicoanalítico apoyando en autores como Freud, Nasio, Foucault, y Lacan, ofrece una propuesta para comprender el fenómeno de la desmovilización como una elección subjetiva. De manera que, el sujeto excombatiente es portador de una responsabilidad simbólica, más allá de las causas o circunstancias sociales que le determinaron vincularse a una organización armada ilegal; el excombatiente tiene que resolver la pregunta por la obediencia ciega y ser dueño de sus elecciones en su singularidad (Castro, 2001), son las propuestas teóricas que orientan su visión sobre el tema.

Con relación a otra perspectiva teórica desde la psicología, el fenómeno de la desmovilización es explicado a través de teorías como: bienestar subjetivo, motivación, calidad de vida; inclusive algunas teorías del enfoque cognitivoconductual son trabajados en las investigaciones, en particular las teorías sobre aprendizaje y disonancia cognitiva. En ese orden de ideas se encuentran investigaciones como: Ávila \& Cogollo, 2011; Blom \& Pereda, 2009; Carmona, 2014; Farfán \& Álzate, 2010; Meneses, Cardona, \& Devia, 2010; Ávila \& Cogollo, 2011, cuyos resultados indican que en el proceso de desmovilización se ubica un nivel medio en la calidad de vida a nivel físico, psicológico y social. Se identifican puntajes altos en aspectos como cansancio, perspectiva de futuro, 
miedo a la muerte y conflictos con personas cercanas. La violencia, maltrato, abusos físicos y sexuales se registran como aspectos motivantes para la desvinculación.

Por otra parte, desde la perspectiva sociológica sobresalen las teorías de Redes sociales, Teoría de habitus y campo y capital de Bourdieu, Imaginario social de Castoriadis, Socialización política de Hannah Arendt, y María Teresa Uribe. Los autores mencionados se inscriben en las investigaciones de: Amar-Amar, Abello, Madariaga \& Ávila, 2011; Céspedes, 2015; Jiménez \& Ramírez, 2016; Londoño \& Blair, 2003.

De lo anterior se colige que las perspectivas teóricas en el marco del análisis sociológico pensado para comprender el fenómeno de la desmovilización señalan la determinación social y cultural para ingresar y salir de la vida armada. Identifican factores como la influencia social, las oportunidades para la reinserción, el regreso a la civilidad entre los motivos para la desmovilización. El concepto de habitus y campo, así como imaginario social son abordados por Céspedes (2015) para demostrar que el proceso de reintegración en Colombia no toma en cuenta las condiciones históricas de los excombatientes y limita el proceso de reinserción a la sociedad a un intercambio de beneficios para ambos actores.

Desde la perspectiva teórica política sobresalen Teorías en Conflicto y Derechos Humanos, Democracia Deliberativa, Justicia Transicional que se ven reflejados en investigaciones de Bácares, 2015; Pérez, 2008; Correa, 2007; Restrepo \& Franco, 2007; Rincón, 2010; Nussio, 2009, donde se analizan la implementación de la Ley 975/2005 que permitió la desmovilización de los grupos paramilitares. Entre los teóricos más representativos se encuentran Alexandra Guáqueta, Clausewitz,
Fisas, Vicenc, Dryzek, John; estos estudios permitieron comprender la dimensión política del fenómeno de la desmovilización, como una respuesta a un sistema de poderes que organizan órdenes locales por encima incluso de la misma lógica estatal.

Con el propósito de analizar e interpretar el proceso de desmovilización con los grupos paramilitares, sus alcances e implicaciones, teóricos como Habermas, Ritzer, Foucault, Giddens, Urlich y algunos autores desde el enfoque epistemologías del sur como Boaventura De Sousa, Zemelman, fueron abordados por investigadores como: Aranguren, 2012; Escobar, 2013; Méndez \& Botero, 2008; Moreno, 2012; Pérez, 2008; Querubín, 2010; Restrepo \& Franco, 2007; Reyes, 2013; Noreña, 2007; Nussio, 2013, concluyendo en la mayoría de las investigaciones un fracaso político, una reorganización sociomilitar y un desgaste económico.

\section{Perspectivas metodológicas}

El fenómeno de la desmovilización de excombatientes a nivel individual y colectivo ha sido estudiado a través de distintos estudios, así como técnicas implementadas. Por lo anterior, se hace necesario resaltar estas aproximaciones o diseños metodológicos para el estudio del fenómeno de la desmovilización (Ver tabla 1).

El análisis de las metodologías permite identificar frente al fenómeno de la desmovilización y su estrategia metodológica que en su mayoría son de corte cualitativo, sobresalen técnicas como entrevistas, historias de vida y grupos focales. Los relatos han sido analizados a través de análisis de contenido, permitiendo el encuentro entre la evidencia empírica y las teorías. Dado el enfoque predominantemente fenomenológico, las narrativas develan aspectos subjetivos en los excombatientes entrevistados. 
Estado de la investigación sobre procesos de desmovilización en excombatientes de grupos al margen de la ley en Colombia (2006-2016)

\section{Tabla 1}

\section{Metodologías utilizadas en las investigaciones sobre desmovilización}

\begin{tabular}{|c|c|c|c|c|}
\hline $\begin{array}{l}\text { Técnica/ Tipo } \\
\text { de } \\
\text { Investigación }\end{array}$ & Cualitativos & Cuantitativos & Mixtos & Histórica \\
\hline Entrevistas & $\begin{array}{c}\text { Aguirre, N. (2014); Castrillón P, G. Y. (2015); Castro } \\
\text { (2001); Cárdenas, S, J. (2005); Céspedes, S,M (2015); } \\
\text { García, J \& Mongua, (2010); Keairns, Y. (2004); Lara } \\
\text { S, L M \& Delgado S, R (2010); Londoño, L M; Blair, } \\
\text { E; (2003); Montalvo V, C (2015); Moreno M, F; } \\
\text { Carmona P, J A \& Tobón H, F; (2010); Moreno, F. } \\
\text { (2012); Noreña, B, H.E (2007); Tamayo C, Restrepo } \\
\text { N, Gutiérrez M,C. (2011) }\end{array}$ & & $\begin{array}{l}\text { Falla, J V; } \\
\text { de la } \\
\text { Espriella, } \\
\text { R; (2009); } \\
\text { Sánchez, R } \\
\text { \& Suárez, } \\
\text { L. (2007); } \\
\text { Theidon, K. } \\
\text { (2009) }\end{array}$ & \\
\hline $\begin{array}{l}\text { Grupos } \\
\text { Focales }\end{array}$ & $\begin{array}{l}\text { Chavarría, (2012); Farfán, O, M.B, \& Álzate, P. C.M } \\
\text { (2010); Jiménez, K. L \& Ramírez V. (2016); } \\
\text { Ocampo, M., Baracaldo, P., Arboleda, L., \& Escobar, } \\
\text { A. (2014); Patiño, C D; Aguirre A, D C; Suárez A, L } \\
\text { A; (2013) }\end{array}$ & & & \\
\hline $\begin{array}{l}\text { Historias de } \\
\text { Vida }\end{array}$ & $\begin{array}{l}\text { Aranguren, J.P (2011); Barrera, A (2014); Castro, M.C } \\
\text { \& Díaz, C.L (1997); Castro, M.C (2001); Castro, M. C } \\
\text { (2002); Leliévre, C. Moreno, G \& Pérez, I. (2004); } \\
\text { Lara, L.M.(2016); Londoño, M (2005); Londoño, M \& } \\
\text { Nieto, F. (2006); Patiño, R. A. \& Patiño, C. D. G. } \\
\text { (2012); Ocampo, M., Baracaldo, P., Arboleda, L., \& } \\
\text { Escobar, A. (2014) }\end{array}$ & & & \\
\hline $\begin{array}{l}\text { Grupos de } \\
\text { Discusión }\end{array}$ & Ugarriza, J.E (2013) & & & \\
\hline Cuestionarios & & $\begin{array}{l}\text { Ávila, J,H \& Cogollo, L. } \\
\text { (2011); Londoño P. C; } \\
\text { Velasco S, R M; (2011); } \\
\text { Meneses, J.R, Cardona, } \\
\text { D, V \& Devia, A (2010); }\end{array}$ & & \\
\hline $\begin{array}{l}\text { Instrumentos } \\
\text { Psicométricos }\end{array}$ & & $\begin{array}{l}\text { Amar-Amar, J., Abello - } \\
\text { Llanos, R., Madariaga, O. } \\
\text { C. \& Ávila-Toscano, J. } \\
\text { H. (2011); Llorente, V. } \\
\text { (2014); Madariaga \& } \\
\text { Ávila (2010); }\end{array}$ & & \\
\hline $\begin{array}{l}\text { Revisión } \\
\text { Documental }\end{array}$ & $\begin{array}{l}\text { Alonso E. M, A; Valencia A. G D; (2008); } \\
\text { Aranguren, J.P (2012); Bácares J, C (2015); Bello, M } \\
\text { \& Ruiz C, S. (2002); Blom, F; Pereda, N (2009); } \\
\text { Cárdenas S, J A; (2006); Castro, M.C. (2006); } \\
\text { Caraballo,(2013); Carmona P, J A (2014); Correa- } \\
\text { Correa, N R; (2007); Castillo \& Salazar, (2009); Díaz, } \\
\text { L. (2002); Echeverría, A. (2007); Escobar, A. (2013); } \\
\text { Grajales, J. (2011); Giraldo \& Mesa (2013); Gunhild, } \\
\text { S \& Luisa M. D. (2007); Gutiérrez, L, Guzmán, A, } \\
\text { Barrera, C, Forero, A, Prada, R, Valderrama, J } \\
\text { (2010)Leal (2013); López, T (2011); Losada, R } \\
\text { (2006); Méndez, M L; Botero, F; (2008); Pérez, B. } \\
\text { (2008); Restrepo, E \& Franco, L (2007); Rincón, } \\
\text { A.(2010); Reyes, A. (2013); Roldán, L (2013); Nasio, } \\
\text { C. (2007); Nussio, E. (2009); Nussio, E. (2011); } \\
\text { Nussio, E. (2013); Querubín, M (2010); Valencia, O L } \\
\text { \& Daza, M F. (2010); }\end{array}$ & & & $\begin{array}{c}\text { Gómez, L. } \\
\text { (2002); Gutiérrez } \\
\text { L, A (2012); } \\
\text { Herrera, D \& } \\
\text { González ,P } \\
\text { (2013); Paz, L. \& } \\
\text { Valencia, G.D. } \\
\text { (2015); } \\
\text { Villarraga S, Á. } \\
\text { (2013); Vizcaíno } \\
\text { B, V J; Molina Á, } \\
\text { M F; (2016) }\end{array}$ \\
\hline
\end{tabular}

Fuente: Los autores. 
La metodología de revisión documental es utilizada por los investigadores en dos escenarios. En primer lugar, la revisión histórica del fenómeno de la desmovilización ha sido desarrollada con bastante fuerza en investigaciones que parten de la explicación del fenómeno en su desarrollo histórico. En segundo lugar, la revisión documental es abordada en investigaciones sobre los procesos de desarme, desmovilización y reintegración con mayor despliegue en los grupos paramilitares.

Las metodologías cuantitativas son utilizadas en estudios explicativos, transversales y correlacionales. Las investigaciones bajo este método han desarrollado instrumentos como el ASSIS que se utiliza para analizar las redes sociales (Sanz \& Menendez, 2003; Hawe, Webster \& Shill, 2004; Lozares, 2005) encuestas, cuestionarios. El análisis de la información se orientó con análisis estadísticos de orden descriptivos y en su mayor porcentaje los participantes fueron excombatientes de grupos guerrilleros y paramilitares que hacían parte del programa de reintegración de la Agencia Colombiana para la Reintegración (ACR).

Las metodologías mixtas han sido trabajadas por medio de la aplicación de instrumentos como encuestas, cuestionarios y entrevistas, en particular por las investigaciones, cuyo propósito consistió en ubicar las causas de la vinculación y motivos de la desmovilización, así como sus consecuencias en áreas como salud mental, redes sociales y vínculos familiares.

En esencia, sobre los problemas de investigación de los 87 documentos revisados; 4 abordaron el problema de reincidencia, 6 el problema sobre las condiciones de vida de los desmovilizados; 18 las consecuencias de la desmovilización, 6 los motivos para la desmovilización y 14 los efectos políticos de la desmovilización. En relación con las perspectivas de abordaje teórico 9 son analizados desde la perspectiva psicosocial, a su vez 2 la perspectiva teórica responde a los subjetivistas y 1 en lo psicológico. Por su parte 24 se enmarcan en abordajes sociológicos y 12 en la perspectiva política. Desde lo metodológico 30 investigaciones utilizaron el método cualitativo, 33 el método de análisis documental, 3 el método mixto (cualitativo/cuantitativo) y finalmente 7 el método cuantitativo.

\section{Conclusiones}

A la luz del objetivo propuesto que consistió en mostrar el estado de la investigación sobre procesos de desmovilización en excombatientes de grupos al margen de la ley entre el periodo (2006 - 2016), se concluye que bajo la perspectiva de las tres categorías que estructuraron el análisis las investigaciones han avanzado en concentrar los esfuerzos en el abordaje de los procesos de desmovilización e forma individual, principalmente.

El estado de la investigación sobre procesos de desmovilización en Colombia en el periodo (2006 - 2016) evidencia grandes contribuciones académicas por parte de investigadores que se han dado a la tarea de abordar el tema desde diferentes categorías y abordajes teóricos, así como metodológicos. La reincidencia de excombatientes aparece como uno de los problemas de investigación trabajados con bastante insistencia frente al proceso de desmovilización con los grupos paramilitares y guerrilleros, en particular en el transcurso de la presidencia de Álvaro Uribe Vélez. (2002-210). Las conclusiones de las investigaciones señalan un empantanado proceso jurídico, toda vez que la implementación de la Ley de Justicia y Paz (9752005) no atendió los vacíos que en el tema de Justicia Transicional fueron reclamados. Además, según lo indicado por las investigaciones varios 
Estado de la investigación sobre procesos de desmovilización en excombatientes de grupos al margen de la ley en Colombia (2006-2016)

excombatientes de los grupos paramilitares conformaron nuevas formas de violencia conocidas como las Bandas Criminales (BACRIM).

Los procesos de desmovilización que se enmarcan en acuerdos de paz han tenido mejor desarrollo en grupos guerrilleros en comparación con grupos paramilitares; sin embargo, excombatientes de las desmovilizadas Milicias Populares de Medellín retornaron a las armas a través de la figura Convivir (1995-1997) que posterior a su disolución conformarían el grupo paramilitar Cacique Nutibara, en la misma ciudad (Paz \& Valencia, 2015).

El gobierno colombiano a través de la (ACR) ha diseñado el programa de reintegración dirigido a los desmovilizados en forma individual o colectiva. En ese contexto, el programa contempla asistencia en salud, educación, vivienda y subsidios económicos por un tiempo determinado, con el ánimo de crear las adecuadas condiciones de vida para los excombatientes y sus familias (Hincapié \& Valencia; 2014); no obstante, el nivel de deserción del programa ha sido alto en parte por la situación de inseguridad hacia los desmovilizados, toda vez que se han presentado asesinatos en contra de esta población y/o la estigmatización propia de su circunstancia de excombatiente (Roldán, 2013).

El análisis de los acuerdos de paz llevados a cabo muestra que la opción política, entendida como participación política, resulta ser el escenario más adecuado para un acuerdo de paz. A diferencia de los acuerdos celebrados con grupos paramilitares, los combatientes de grupos guerrilleros han dado prioridad hacia la participación política (asociaciones, fundaciones, partidos políticos) señalando mejores resultados en el proceso hacia la reintegración.
Las diferencias por los motivos para la desmovilización a nivel individual y colectivo y entre excombatientes de grupos guerrillero o paramilitares ofrecen una ruta consecuente y lógica a la hora de entender el retorno o no a la ilegalidad. Desde este panorama, cuando la decisión por la desmovilización es individual, difícilmente el excombatiente retorna a las armas, a diferencia de cuando la decisión es por orden directa o fruto de una negociación política y en especial con grupos paramilitares cuyo regreso a la vida armada es mayor (Lara, 2016; Londoño, 2005).

Finalmente, las investigaciones revisadas avanzan hacia la comprensión del fenómeno de la desmovilización, sus consecuencias, implicaciones, características y formas de desmovilización, las cuales han sido estudiadas y analizadas a través de distintas propuestas teóricas; sin embargo, la literatura se reduce al momento de relacionarse con el sujeto combatiente que toma la decisión por la desmovilización en forma individual.

Dirigir la atención hacia los excombatientes (desertores) en sus procesos de construcción de la decisión por la desvinculación del grupo armado ilegal, contribuirá a develar el carácter subjetivo del acto por la desmovilización. Por lo que se considera necesario adelantar estudios que reflexionen en el sujeto combatiente que se juega la vida al momento del ingreso y salida del grupo ilegal, el sujeto excombatiente que comporta cierta fractura subjetiva, el combatiente en el cual se tramita una cadena de significación identitaria; pasar a ser (desertor) adquiere otros niveles de reflexión que no deben ser pasados por el anonimato, y en cuya decisión reposan las pistas para un buen proceso de reintegración. Las investigaciones revisadas se agotan en la reflexión por el sujeto (desertor) no obstante, avanzan en la comprensión del fenómeno de desmovilización desde lo psicológico, político, y 
sociológico.

La experiencia de la guerra abre así mismo la ocasión de la perplejidad del sujeto encarado a su acto. Para cada sujeto, la guerra llega a su fin cuando renuncia al discurso guerrero y con ello a la postura enaltecida y al poderío que aglutina formando colectivo. En lo fundamental, se trata de un paso íntimo que implica una pérdida subjetiva, cuyos efectos perfilan la tragedia de aquel que durante un tiempo sólo ha sabido del oficio de la guerra, como trasfondo del drama que se inaugura cuando la contienda bélica termina o cuando se sale de ella. (Castro, 2006, p.134)

La desmovilización individual supone la renuncia a un colectivo, a un proyecto político, a unas causas que lo condujeron a ingresar a la guerra y a unas causas que le llevaron a salir de la misma. La desmovilización individual determina un retorno a esa misma sociedad con la que se luchó, la desmovilización entraña cierta fractura subjetiva y colectiva. El análisis de la desmovilización y su configuración (personalidad social del sujeto) es donde se juega precisamente esa inconformidad que lo llevo a la rebelión armada; es decir, una inconformidad con la estructura social existente, pues se trata precisamente de una renuncia a su motivación resistente, quizás un arrepentimiento a la causa revolucionaria, bien sea porque la degradación de la guerra hace inoperante el estar, bien sea porque las acciones del grupo van perdiendo credibilidad, bien sea porque cambió el contexto.

En la desmovilización se juega el sujeto en su decisión, en sus elecciones subjetivas, una cierta emergencia del "no puedo más" que sería una expresión de lo singular del sujeto hace que ocurra la decisión por la desmovilización y es que el proceso mismo de la desmovilización implica de entrada un asumir la estructura como dada, como inamovible, como correcta; lo que deriva en un sentido que desmovilizarse señala una especie de darse cuenta del error, de la mala decisión, de resarcir las consecuencia de aquella decisión de vida, una especie de súbito arrepentimiento, una equivocación, un paso mal dado, o quizás una decepción.

La elección por la guerra implica a un sujeto en su singularidad, en sus actos y en sus claudicaciones, la guerra es un punto de encuentro de sujetos que en cierta manera deciden por ésta como una forma de tramitar su apuesta subjetiva, es el lugar asumido frente a la sociedad y frente a sí mismo; la guerra opera como un dispositivo de anclaje de historias, narrativas, circunstancias, es un colectivo en acto, en donde pareciera ser que el sujeto combatiente se desdibuja en la masa, en las formas de simbolización propias al colectivo o ideología en que se inscribe. Hablar de un sujeto excombatiente señala hablar de un sujeto escindido en un antes, durante y después de su paso por la guerra, más allá de las razones que justificaron su ingreso o salida del grupo armado.

\section{Anexo 1 Acuerdos de paz}

Acuerdo de paz con el M-19

Bogotá, marzo 9 de 1990. Entre los aspectos políticos se encuentra: Fortalecer la legitimidad institucional, crear mecanismos de paz y ampliar espacios democráticos. Participación política. El gobierno promoverá la incorporación de la guerrilla a la vida civil y su tránsito a la vida política para lo cual respaldará la conformación de una circunscripción especial de paz. Promover la incorporación guerrillera a la vida civil. Entre los aspectos económicos y sociales: Activar el Fondo Nacional para la paz en las zonas de influencia guerrillera en pro del beneficio comunitario. 
Estado de la investigación sobre procesos de desmovilización en excombatientes de grupos al margen de la ley en Colombia (2006-2016)

Seguridad alimentaria. Vivienda. Salud. Políticas laborales y de ingresos salarios. Entre los aspectos de Derechos Humanos: Crear una comisión asesora para la reforma integral de la justicia del más alto nivel. Aspectos de la reinserción. El Consejo Nacional de Normalización coordinará el plan de desmovilización, la reinserción social y productiva, así como el plan de seguridad. (Villarraga, 2015, p 61)

Acuerdo de paz con el Partido Revolucionario de Trabajadores PRT

Ovejas - Sucre enero 25 de 1991. Entre los aspectos políticos se encuentra: Participación en la Asamblea Nacional Constituyente. Legalización como partido político. Celebración cívica de la dejación de las armas. Creación de casas por la vida. Aspectos económicos y sociales. Establecer planes regionales de inversión en beneficio de las comunidades sobre la base de la participación y la concertación. Aspectos Derechos Humanos. Crear una oficina delegada de la Consejería Presidencial para los DD. HH en la Costa Atlántica. Aspectos de la reinserción. El gobierno garantizará los recursos y el PRT cumplirá programas y acciones. Subsidio de vida por 6 meses prorrogables. Gastos de atención en salud. Alfabetización y educación formal acelerada. Capacitación. Proyectos productivos y de servicios con créditos de 2 millones de pesos. Estudios postsecundarios, constitución de un fondo de becas y créditos de 2 millones de pesos. Empleo estable gestionado por el gobierno. Plan de seguridad. (Villarraga, 2015, p 61)

Acuerdo de paz con el Ejército Popular de Liberación EPL

Bogotá, febrero 15 de 1991. Entre los aspectos políticos. Participación en la Asamblea Nacional Constituyente. Legalizar su partido político.
Apertura de casas de la democracia y comités operativos regionales. Auxilio por quince millones de pesos a la fundación Progresar. Gira de dos miembros del EPL por Europa y América Latina. Aspectos económicos y sociales. Crear una comisión bilateral para definir los municipios y las prioridades presupuestales. Crear consejos municipales por la paz. Aspectos en Derechos Humanos. Crear una comisión hacia la superación de la violencia. Atender a las víctimas por actos de violencia política. Aplicar el Derecho Internacional Humanitario. Aspectos de la reinserción. La fundación Progresar canalizará esfuerzos y recursos de apoyo. Educación no formal. Participación ciudadana y comunicación popular. Auxilio mensual de 150 pesos por 6 meses prorrogables. Servicio de salud. Proyecto productivo con capacitación, asistencia técnica y créditos por 2 millones de pesos. Fondo de créditos para estudios superiores. Ubicación laboral. Plan de seguridad. (Villarraga, 2015, p 89)

Acuerdo de paz con el Movimiento Armado Quintín Lame (MAQL)

Caldono - Cauca, mayo 27 de 1991. Entre los aspectos políticos. Contar con voceros permanentes sin voto ante la Asamblea Nacional Constituyente. Establecer un auxilio económico de dos y medio millones de pesos para los gastos de siete voceros promotores del proceso de paz. Siete millones de pesos para la fundación (Sol y Tierra) y financiación de sedes para ésta fundación. Financiar el hospedaje y la alimentación de su vocero ante la Asamblea Nacional Constituyente y dos escoltas. Aspectos económicos y sociales. Realizar obras regionales de desarrollo por 600 millones de pesos para el beneficio de los municipios señalados de común acuerdo. El Consejo de Normalización del Cauca decidirá las obras y su monto por cada municipio. Aspectos en Derechos Humanos. Permitir que dos excombatientes del MAQL for- 
men parte de la Comisión para la Superación de la Violencia. Aspectos de la reinserción. Auxilio mensual de subsistencia por 6 meses prorrogables por un monto de 12 millones de pesos. Salud. Educación no formal. Proyectos productivos con créditos por 2 millones de pesos que incluya capacitación técnica. Plan de seguridad. (Villarraga, 2015, p 85)

Acuerdo de paz Comando Ernesto Rojas (CER) Bogotá, marzo 20 de 1992.

Aspectos políticos. Participación política. Aspectos económicos y sociales. Poner en marcha un plan de reinserción. Presencia de un representante ante la dirección del Programa para la Reinserción. Gestionar la salida al exterior de tres excombatientes y habilitar a otros el porte legal de armas. (Villarraga, 2015, p 91)

Acuerdo de paz Corriente de Renovación Socialista (CRS)

Flor del Monte - Sucre, abril 9 de 1994. Aspectos políticos. Contar con dos miembros en la Cámara de Representantes durante el periodo 1994 - 1998. Impulsar proyectos de Ley sobre participación y concertación. Fortalecer las labores del Instituto para el desarrollo de la democracia. Activar el fondo para la participación ciudadana. Aspectos económicos y sociales. Fomentar el desarrollo regional en zonas de conflicto mediante programas de inversión social. Destinar recursos por 50 millones de pesos para el fondo de vivienda de la corporación "Arco Iris". Crear un programa de dotación de tierras en el municipio de Ovejas - Sucre. Derechos Humanos reinserción política y análisis de la situación de los DD.HH. Aspectos reinserción. Apoyo de $170 \mathrm{mil}$ pesos por un año. Servicio de salud. Programa educativo y apoyo psicosocial. Capacitación y asistencia técnica para proyectos productivos. Vivienda. Aplicación del programa de dotación de tierras para miembros de grupos desmovilizados. Créditos individuales por 4 millones de pesos y 600 millones de pesos para la corporación “Arco Iris”. Programa de seguridad. (Villarraga, 2015, p 96)

\section{Acuerdo de paz Milicias de Medellín}

Medellín, mayo 26 de 1994. Aspectos políticos. Incluir a Medellín dentro del área de aplicación de circunscripciones electorales especiales que incorporen la organización o movimiento político que se derive de la organización armada. Participación de excombatientes en las juntas de acción local. Participación de excombatientes en las reuniones de planeación e inversión social. Aspectos económicos y sociales. Realizar obras de inversión social en las comunas 1,2,3,4,5 y 6 de Medellín. (Obras de infraestructura vial, y de servicios educación, salud, recreación y deportes. Normalización de la vida ciudadana. Construcción de viviendas. Capacitación empresarial. Conformar una policía comunitaria. Plan de convivencia y seguridad. Derechos Humanos. Conformar la Fundación para la Convivencia Ciudadana en las comunas nororientales de Medellín. Aspectos de reinserción. Participación en la administración pública comunitaria. Inserción laboral. Educación. Salud. Vivienda. Proyectos productivos con créditos de 3 millones de pesos. Plan de seguridad.

\section{Acuerdo de paz Frente Francisco Garnica (FFG) Cañaveral - Bolivar, junio 30 de 1994.}

Aspectos políticos. Establecer circunscripciones electorales especiales en donde el frente tuvo presencia y en ellos a la organización o movimiento político que se derive del grupo guerrillero. Aspectos de reinserción. La Fundación "Colombia Viva” recibirá 40 millones de pesos para pro- 
Estado de la investigación sobre procesos de desmovilización en excombatientes de grupos al margen de la ley en Colombia (2006-2016)

mover el proceso y presentar proyectos productivos. Auxilio económico por 140 mil pesos por un año. Salud. Educación. Proyectos productivos, asistencia técnica para construir una organización de vivienda y gestión de créditos por 3 millones de pesos. Plan de seguridad. (Villarraga, 2015, p 97)

\section{Referencias}

Aguirre, N. (2014) Después de la guerra: el individuo, el grupo y la relación de confianza. Tendencias \& Retos, 19(2), 109-121.

Alonso E. M, A; Valencia A. G D; (2008). Balance del proceso de Desmovilización, Desarme y Reinserción (DDR) de los bloques Cacique Nutibara y Héroes de Granada en la ciudad de Medellín. Estudios Políticos. 11-34. Recuperado de https://goo.gl/XtbNCX

Aranguren, J.P. (2012) Las inscripciones de la guerra en el cuerpo de los jóvenes combatientes: historias de cuerpos en tránsito hacia la vida civil. Revista Maguré 26 (2). 274-276.

Aranguren, J.P. (2012) Reinserción sin desmovilización: de las AUC a las Bacrim. La gestión del testimonio y la administración de las víctimas: el escenario transicional en Colombia durante la Ley de Justicia y Paz. Bogotá: Siglo del Hombre Editores y CLACSO.

Amar-Amar, J., Abello Ll, R., Madariaga, O. C. \& Ávila-Toscano, J. H. (2011). Relación entre redes personales y calidad de vida en individuos desmovilizados del conflicto armado colombiano. Universitas Psychological, 10(2), 355-369.

Ávila, J.H. \& Cogollo, L. (2011). Motivos asociados a la conducta violenta contra la pareja en hombres desmovilizados del conflicto armado. Revista Investigación y Desarrollo. 19(1) 88-115. Colombia: Universidad del Sinú.

Ávila-Toscano, J., \& Madariaga Orozco, C. (2010).
Redes personales y dimensiones de apoyo en individuos desmovilizados del conflicto armado. Psicología desde el Caribe, (25), 179-201. Recuperado de: http://www.redalyc.org/pdf/213/21315106009.pdf

Bácares J, C; (2015). Los niños, niñas y jóvenes desvinculados de los grupos armados ilegales en Colombia: ¿Víctimas de la violencia política o sujetos del delito? Estudios Socio-Jurídicos, 17, 233-262. Recuperado de https://goo.gl/xjdWzD

Barrera, A. (2014). Reflexiones a propósito de los relatos de tres mujeres excombatientes: apuntes sobre sus trayectorias de vida y sus nociones de paz. Revista de Ciencia Política. 9, 181-212.

Bello, M. \& Ruiz C, S. (2002). (Editoras). Conflicto Armado Niñez y Juventud. Una perspectiva psicosocial. Bogotá: Universidad Nacional de Colombia.

Blair, E., \& Londoño, L. (2003). Experiencias de guerra desde la voz de las mujeres. Nómadas, (19), 106-115. Recuperado de https:// goo.gl/y4W9TZ

Blom, F., \& Pereda, N. (2009). Niños y niñas soldado: consecuencias psicológicas e intervención. Anuario de Psicología, 40 (3), 329344. Recuperado de https://goo.gl/CQwULs Botero, F., \& Méndez, M. (2008). ¿Reír o Llorar? El drama del conflicto y la resiliencia de la economía en Colombia, 2007. Revista de Ciencia Política, 28 (1), 121-145. Recuperado de https://goo.gl/5NFkis

Caraballo Acuña, V. (2013). Órdenes locales, acuerdos de paz y presencia diferenciada del Estado. Negociación con las Milicias Populares de Medellín. Colombia Internacional, (77), 241-270. Recuperado dehttps://goo.gl/ bg7nfV

Cárdenas, S, J. (2005). Los parias de la guerra. 
Análisis del proceso de desmovilización individual. Bogotá: Ediciones Aurora.

Cárdenas Sarrias, J. (2006). Los Renegados de Antaño y Hogaño: Desmovilización de Excombatientes Irregulares en Colombia. Tesis Psicológica, (1), 53-70. Recuperado de https:// goo.gl/hzsD4v

Carmona, P. J. ( 2012). La carrera de las niñas en los grupos guerrilleros y paramilitares de Colombia: un estudio desde el punto de vista del agente. Medellín: Fundación Luis Amigó.

Carmona Parra, J. (2014). Definición de la situación de los menores desvinculados de los grupos armados ilegales en los actos jurídicos y sus efectos psicoeducativos. Revista Estudios Socio-Jurídicos, 16 (2), 163-177. Recuperado de https://goo.gl/upMCex

Castillo, M., \& Salazar, B. (2009). ¿Cuánto vale desertar? Revista de Economía Institucional, 11 (20), 199-227. Recuperado de https:// goo.gl/GDQeXG

Castrillón, Pulido. G, Y. (2015). ¿Víctimas o victimarias? El rol de las mujeres en las FARC. Una aproximación desde la teoría de género. Revista Ópera. 77-95. Recuperado de https://goo.gl/pmFWKh

Castro, M. C. (2002). Jóvenes guerreros: elecciones, pasajes y pasos. En: Martha Bello y Sandra Ruiz (Eds.) Conflicto armado, niñez y juventud: Una perspectiva psicosocial. 7790. Bogotá: Universidad Nacional de Colombia y Fundación Dos Mundos.

Castro, M.C. (2001). Del ideal y el goce: lógicas de la subjetividad en la vía guerrillera y avatares en el paso a la vida civil. Bogotá: Universidad Nacional de Colombia.

Castro, M.C \& Díaz, C.L (1997). Guerrilla, reinserción y lazo social. Bogotá: Editores Almudena.

Castro, M.C. (2006). La Guerra: una experiencia sin fin. Revista Colombiana de Psicología, 15, 131-135. Recuperado de https://goo.gl/ AePkks

Céspedes, S., M. (2015). Disposiciones, trayectorias e imaginarios sociales de Estado y ciudadanía en el proceso de reintegración de guerrilleros y paramilitares en Colombia. Revista Colombiana de Sociología, 38(1), 185 - 209.

Correa-Correa, N. (2007). Reinserción y reparación. Vniversitas, (114), 251-289. Recuperado de https://goo.gl/

Chavarría Olarte, G. (2012). Estrategias utilizadas para la satisfacción de la garantía de no repetición en desmovilizados de grupos armados ilegales: un estudio con desmovilizados de grupos paramilitares de las Autodefensas Unidas de Colombia. Medellín, Valle de Aburrá - Colombia. Revista Facultad de Derecho y Ciencias Políticas, 42 (116), 195252. Recuperado de https://goo.gl/

Díaz, L. (2002) Niños y niñas en el conflicto armado: ¿Víctimas o actores? En: Martha Bello y Sandra Ruiz (Eds.), Conflicto Armado Niñez y Juventud. Una perspectiva psicosocial, 65-76. Bogotá: Universidad Nacional de Colombia \& Fundación Dos Mundos.

Escobar, A. (2013). Desarme, desmovilización y reintegración en Camboya. Colombia Internacional 77, 73-105. Recuperado de https:// goo.gl/PfTrfY

de la Espriella, R., \& Falla, J. (2009). Reflexiones sobre la atención en salud mental de desmovilizados de grupos armados en Colombia. Revista Colombiana de Psiquiatría, 38(2), 230-247. Recuperado de http://www.redalyc.org/pdf/806/80615421002.pdf

Farfán, O., M., B, \& Álzate, P., C., M. (2010). Factores motivacionales de la población en proceso de reintegración social y económica para su ingreso y permanencia en el sistema 
Estado de la investigación sobre procesos de desmovilización en excombatientes de grupos al margen de la ley en Colombia (2006-2016)

educativo, área metropolitana de Risaralda durante el año 2010: estudio cualitativo realizado con participantes del proceso de reintegración en el área metropolitana de Risaralda. Universidad de Manizales - CINDE: Centro de Estudios Avanzados en Niñez y Juventud alianza de la Universidad de Manizales y el CINDE.

García, J. \& Mongua., C. (2010). El M-19 y una reflexión acerca de las guerras inútiles. Revista de Ciencias Sociales. (37), 123-131. Recuperado de https://goo.gl/QRVgWU

Giraldo, G. (2010). Contextualización teórica e histórica de la reintegración social y económica de desmovilizados en Colombia. Revista Académica y Cultural. 6(11), 35-51. Recuperado de https://goo.gl/uyQpdM

Giraldo Ramírez, J., \& Mesa Mejía, J. (2013). Reintegración sin desmovilización: el caso de las milicias populares de Medellín. Colombia Internacional, (77), 217-239. Recuperado de https://goo.gl/CqH2cX

Gómez, L. (2002). Reflexiones acerca de los procesos de paz en Colombia: Marco Jurídico Y Otras Consideraciones. Revista de Derecho, Universidad del Norte. Barranquilla - Colombia.

Gómez Araujo, L. (2002). Reflexiones acerca de los procesos de paz en Colombia. El marco jurídico y otras consideraciones. Revista de Derecho, (18), 118-134. Recuperado de https://goo.gl/RWi4b4

Grajales, J. (2011). El proceso de desmovilización de los paramilitares en Colombia: entre lo político y lo judicial. Desafíos 23-II, 149194. Recuperado de https://goo.gl/Rau8r2

Gunhild, S. \& Luisa M. D. (2007). La desmovilización de las mujeres excombatientes en Colombia. Revista Migraciones Forzadas, (27), 58-59. Recuperado de https://goo.gl/ yBRDbS
Gutiérrez, L., Guzmán, A., Barrera, C., Forero, A., Prada, R., Valderrama, J. (2010). La mirada prejuiciosa de la prensa a los reinsertados. Signo y Pensamiento, V. XXIX (56), 376387. Recuperado de file://C:/Users/editorial/Downloads/2568-8891-2-PB.pdf

Gutiérrez Loaiza, A. (2012). Negociaciones de paz en Colombia, 1982-2009. Un estado del arte. Estudios Políticos, (40), 175-200. Recuperado de https://goo.gl/Fnwu86

Hübschmann, J (2016) Apoyo a la Organización de los Estados Americanos en la atención a víctimas en Colombia. Deutsche Gesellschaft für Internationale Zusammenarbeit (GIZ) GmbH. Disponible en https://www. giz.de/en/downloads/giz2016-Factsheet_ Mapp-OEA_esp.pdf

Herrera, Dylan, \& González, Paola. (2013). Estado del arte del DDR en Colombia frente a los estándares internacionales en DDR (IDDRS). Colombia Internacional, (77), 272302. Recuperado de https://goo.gl/52a2Li

Hincapié Salazar, S., \& Valencia Agudelo, G. (2014). Incentivos económicos para la desmovilización de la insurgencia en Colombia. Perfil de Coyuntura Económica, (24), 49-69. Recuperado de https://goo.gl/zE3A9z

Jiménez Gómez, K., \& Ramírez Loaiza, V. (2016). Aproximaciones a la subjetividad y socialización política de jóvenes excombatientes del conflicto armado en Colombia. Trabajo Social, 0(18), 77-90. Recuperado de https:// goo.gl/UQRBbZ

Keairns, Y. (2004). Voces de jóvenes excombatientes. Recuperado de https://goo.gl/rvZBbF

Lara Salcedo, L., \& Delgado Salazar, R. (2010). Trasegar de las subjetividades y las memorias de las y los jóvenes desmovilizados en el tránsito a la vida civil. Una mirada a los programas educativos y de apoyo psicosocial. Universitas Humanística, (70), 29-56. 
Recuperado de https://goo.gl/ayMWrp

Leal Buitrago, F. (2013). Participación política de desmovilizados: Universidad Nacional de Colombia y Naciones Unidas, 28 de abril de 2013. Revista de Estudios Sociales, (47), 177181. Recuperado de https://goo.gl/CPT8wx Leliévre, C. Moreno, G. \& Pérez, I. (2004). Haciendo memoria y dejando rastros. Encuentros con mujeres excombatientes del Nororiente de Colombia. Bogotá: Fundación mujer y futuro - UNIFEM. Recuperado de https:// goo.gl/vBJJE4

Londoño, L. (2005). La corporalidad de las guerreras: una mirada sobre las mujeres combatientes desde el cuerpo y el lenguaje. Revista de Estudios Sociales, (21), 67-74. Recuperado de https://goo.gl/kJsn7y

Londoño, M. \& Nieto, F. (2006). Mujeres no contadas: procesos de desmovilización y retorno a la vida civil de mujeres excombatientes en Colombia. 1990 - 2003. Medellín: Editorial Lealon.

Losada, R. (2006). IMPLICACIONES ELECTORALES DE LA REINSERCIÓN POLÍTICA DE LAS AUTODEFENSAS EN COLOMBIA. Papel Político, 11 (1), 11-45. Recuperado de https://goo.gl/Wy9qQY

Meneses, J.R, Cardona, D, V \& Devia, A (2010). Calidad de vida en sujetos que pertenecen al programa nacional de desmovilización y reincorporación a la vida civil en el departamento del Quindío. El Agora, Revista de Ciencias Sociales, 19 (1) 71-86. Recuperado de: http://revistas.usbbog.edu.co/index. php/Agora/article/view/365/125

Molina Álvarez, M., \& Vizcaíno Barrera, V. (2016). Procesos de desmovilización de las Autodefensas Unidas de Colombia y el Frente Farabundo Martí para la Liberación Nacional en el marco de la Ley de Justicia y Paz en Colombia y los Acuerdos de Paz de Chapul- tepec en El Salvador. Memorias. Revista Digital de Historia y Arqueología desde el Caribe, (28), 228-262. Recuperado de https:// goo.gl/4nrgKt

Montalvo Velásquez, C (2015). Principio de oportunidad frente al adolescente desmovilizado del conflicto: un postulado del derecho penal mínimo y una política pública que genera impunidad penal. Justicia Juris, 11(1), 7188. Recuperado de https://goo.gl/P4HpK7

Moreno Martín, F., \& Carmona Parra, J., \& Tobón Hoyos, F. (2010). ¿Por qué se vinculan las niñas a los grupos guerrilleros y paramilitares en Colombia? Revista Latinoamericana de Psicología, 42 (3), 453-467. Recuperado de https://goo.gl/doRDzQ

Nasi, C. (2007). Cuando callan los fusiles. Impacto de la paz negociada en Colombia y en Centroamérica. Bogotá: Grupo Editorial Norma-Universidad de los Andes.

Noreña, B, H.E. (2007). Los paramilitares en Medellín: la desmovilización del Bloque Cacique Nutibara. Recuperado de https://goo.gl/ PYUuQ1

Nussio, E. (2009). ¿Reincidir o no? Conceptos de la literatura internacional aplicados al caso de desarme, desmovilización y reintegración de las Autodefensas Unidas de Colombia. Pensamiento Jurídico, 0(26), 213-236. Recuperado de https://revistas.unal.edu.co/ index.php/peju/article/view/36565

Nussio, E. (2011) DDR en Colombia: caso especial. En ed. Rocío Rubio. pp. 47. DDR en clave de prospectiva, posibles escenarios de futuro para Colombia. Fundación Social, Konrad Adenauer Stiftung. Bogotá.

Nussio, E. (2013). Desarme, desmovilización y reintegración de excombatientes: políticas y actores del posconflicto. Colombia Internacional 77, 8-16. Recuperado de https://goo. $\mathrm{gl} / \mathrm{xcqd} \mathrm{M}$ 
Estado de la investigación sobre procesos de desmovilización en excombatientes de grupos al margen de la ley en Colombia (2006-2016)

Ocampo, M., Baracaldo, P., Arboleda, L., \& Escobar, A. (2014). Relatos de vida de mujeres desmovilizadas: Análisis de sus perspectivas de vida. Informes Psicológicos, 14(1), 109128. Recuperado de https://goo.gl/3ppwQH Patiño, O. R. A. \& Patiño, G. D. G. (2012). Configuración de la identidad de desertores de la guerrilla colombiana. Psicología \& Sociedad, 24(3), 517-526. Recuperado de https:// goo.gl/rCQYru

Suárez Álvarez, L., \& Patiño, C., \& Aguirre Acevedo, D. (2013). Las representaciones sociales del enemigo: la organización de un campo en tensión. CES Psicología, 6 (1), 159-179.

Pérez, B. (2008). El acuerdo pactado: ¿Desmonte o legalización de la acumulación paramilitar? Revista de Economía Institucional, 10(18), 397-406.

Querubín Londoño, M. (1998). Las negociaciones de paz y el papel de la Sociedad Civil. Revista de Estudios Sociales, (2).

Restrepo Echeverri, J., \& Franco Restrepo, V. (2007). Dinámica reciente de reorganización paramilitar en Colombia. Revista Controversia, 0(189), 64-95. Recuperado de https:// goo.gl/b6fiH6

Rincón, A. (2010). Del cese al fuego a la paz sostenible: desafíos contemporáneos de la Justicia Transicional. Revista Análisis Internacional. (2),129-146.

Roldán, L. (2013). La Inclusión laboral de los desmovilizados del conflicto en Colombia: Auténtico mecanismo emancipador de la violencia en Colombia. Universitas Estudiantes, 10, 103-119. Recuperado de: https://goo.gl/ SF46Pr

Tamayo, C., Restrepo, N., Gutiérrez, M.C. (2012). Diagnóstico del proceso educativo en salud de la población desmovilizada del municipio de Medellín, Antioquia 2011. CES Salud Pública. 3(2), 141-151.
Theidon, K. (2009). Reconstrucción de la masculinidad y reintegración de excombatientes en Colombia. Working Papers 5. Bogotá: Fundación Ideas para la paz.

Llorente, V. (2014.) Retorno a la legalidad o reincidencia de excombatientes en Colombia: Dimensión del fenómeno y factores de riesgo. Informe No. 22. Bogotá: Fundación Ideas para la paz.

Rampf, D. \& Chavarro, D. (2005). Entrar en la escena política. Un análisis de las experiencias de exguerrilleros en la política legal colombiana. En Guerrero, G. L. \& Giessmann, H.J. (Eds.), Colección Papeles de Paz. Renunciar a la opción armada. Experiencia de reintegración política de grupos insurgentes en Colombia y El Salvador. (pp.10-30). BogotáCinep y Berlín - Fundación Berghof.

Restrepo Echeverri, J., \& Franco Restrepo, V. (2007). Dinámica reciente de reorganización paramilitar en Colombia. Revista Controversia, 0(189), 64-95. Recuperado de https://goo.gl/J3hYp7

Roldán, Castellanos. L. (2013). La inclusión laboral de los desmovilizados del conflicto en Colombia: Auténtico mecanismo emancipador de la violencia en Colombia. Universitas Estudiantes. (10), 103-119. Recuperado de https://goo.gl/zrDYts

Sánchez, R. \& Suárez, L. (2007). Un modelo de regreso a la legalidad. Desafíos, Bogotá (Colombia), (17): 102-125, semestre II.

Ugarriza, J. E. (2013). La dimensión política del postconflicto. Discusiones conceptuales y avances empíricos. Colombia Internacional 77, 141-176.

Valencia, O., \& Daza, M. (2010). Vinculación a grupos armados: un resultado del conflicto armado en Colombia. Diversitas: Perspectivas en Psicología, 6 (2), 429-439. Recuperado de https://goo.gl/U1VVw4 
Velasco Salamanca, R., \& Londoño Pérez, C. (2011). Calidad de vida objetiva, optimismo y variables socio-jurídicas, predictivos de la calidad de vida subjetiva en colombianos desmovilizados. Avances en Psicología Latinoamericana, 29 (1), 114-128. Recuperado de https://goo.gl/uACNZe

Villarraga Sarmiento, Á. (2013). Experiencias históricas recientes de reintegración de excombatientes en Colombia. Colombia In- ternacional, (77), 107-140. Recuperado de https://goo.gl/W4iSVs

Villarraga Sarmiento, A. (2015). Biblioteca de la Paz 1980 - 2013. Los procesos de paz en Colombia, 1982 - 2014 (Documento Resumen) Bogotá: Fundación Cultura Democrática: Bogotá. Recuperado de http://biblioteca. ucp.edu.co/Descargas/core/documentos/2. 